\title{
Long-term skeletal stability following orthognathic surgery with counter-clockwise and clockwise rotation of the maxillo-mandibular complex: report of three cases
}

\author{
Rafael Correia Cavalcante $^{1 \wedge}$, Otávio Giambarresi Delorenzi ${ }^{2}$, Leandro Eduardo Kluppel $^{3}$ \\ ${ }^{1}$ Department of Oral and Maxillofacial Surgery, Bupa Care Plus Assistencial Medicine, São Paulo, Brazil; ${ }^{2}$ Department of Oral and Maxillofacial \\ Surgery, Federal University of Paraná, Paraná, Brazil; ${ }^{3}$ Department of Oral and Maxillofacial Surgery, Federal University of Paraná, Paraná, Brazil; \\ Correspondence to: Rafael Correia Cavalcante. Department of Oral and Maxillofacial Surgery, Bupa Care Plus Assistencial Medicine, São Paulo, Brazil. \\ Email: rafaelcorreia14@gmail.com.
}

\begin{abstract}
Background: The aim of the present study is to evaluate the long-term postoperative skeletal stability after orthognathic surgery with counter-clockwise rotation (CCWR) or with clockwise rotation (CWR) of the maxillo-mandibular complex.

Case Description: Three patients were submitted to orthognathic surgery associated with CCWR and CWR. Lateral cephalometric radiographs were obtained in centric relation for each patient, one day before surgery (T1), 1 week after surgery (T2) and 1 year after surgery (T3). Cephalometric angles analysed were: SN-OP, SN-A, SN-B, SN-Pg, and SN-Ar. Angular changes on occlusal plane (OP), condylar position, maxilar, mandibular, and pogonium prognathism were analysed. Maxilar, mandibular, and pogonium prognathism linear changes were also recorded in millimeters. Patients had no signs and symptoms of temporo-mandibular joints pathology. Patients 1 and 2 were submitted to orthognathic surgery with CCWR. Patient 1 presented an OP decrease on T2, from $6.37^{\circ}$ to $4.01^{\circ}$. On T3, however, a $2.17^{\circ}$ relapse was observed. Patient 2 presented an $\mathrm{OP}$ decrease on $\mathrm{T} 2$, from $8.14^{\circ}$ to $3.45^{\circ}$. On T3, however, a $0.54^{\circ}$ relapse was observed. Patient 3 was submitted to orthognathic surgery with CWR. It was observed an increase in OP angulation on $\mathrm{T} 2$, from $6.16^{\circ}$ to $16.13^{\circ}$. On T3, however, it was observed a $7.57^{\circ}$ relapse.

Conclusions: Regarding OP stability following orthognathic surgery with CCWR and CWR, results of the present article are consistent with of some previous published studies. More cases should be followed and more research in this area are necessary to validate these approaches to avoid unsuccessful cases or to anticipate unwanted results.
\end{abstract}

Keywords: Orthognathic surgery; dentofacial deformities (DDF); maxillofacial abnormalities; case report

Received: 26 May 2020; Accepted: 23 February 2021; Published: 30 March 2021.

doi: $10.21037 /$ fomm-20-32

View this article at: http://dx.doi.org/10.21037/fomm-20-32

\section{Introduction}

Dentofacial deformities (DDF) correction usually require orthognathic surgery aiming good functional and aesthetic results. Occlusal Plane (OP) angle is defined as the angle formed by the Frankfort horizontal plane and a line tangent to canine tips of lower premolars and buccal groove of second molars. Normal values in adults is $8^{\circ} \pm 4^{\circ}$. DDFs are usually related to an abnormal angulation of OP, and this angle surgical modification may have an important impact on functional and aesthetics outcomes $(1,2)$.

Two basic facial types may benefit from OP surgical alteration: high occlusal plane (HOP) dolichocephalic morphologic type, and low occlusal plane (LOP)

$\wedge$ ORCID: 0000-0001-6466-5165. 


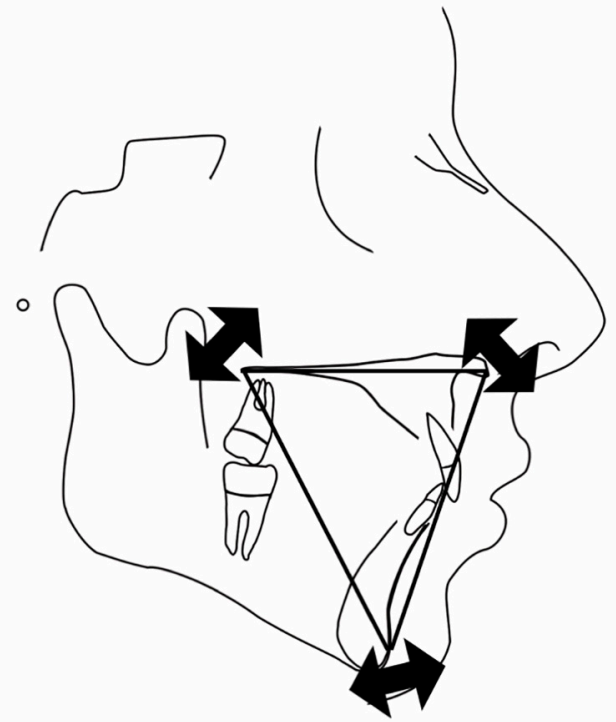

Figure 1 Maxillo-mandibular complex represented as a triangle, which may be rotated in clockwise (CWR) or counter-clockwise (CCWR) direction according to the aesthetics requirements.

brachycephalic morphologic type. HOP facial type presents some features such as: increased $\mathrm{OP}$ angulation $\left(\mathrm{OP}>12^{\circ}\right)$; anterior vertical maxillary hyperplasia and/or posterior vertical maxillary hypoplasia; anteroposterior mandibular hypoplasia; high mandibular plane angulation; and Class I, Class II (most common), or Class III malocclusion with or without an anterior bite. HOP individuals may benefit from a MMC counterclockwise rotation (CCWR). LOP facial type presents some features: decreased OP angle $\left(<4^{\circ}\right)$; low mandibular plane angle; prominent mandibular gonial angles; strong chin relative to mandibular dental alveolus; and Class I, Class II, or occasionally Class III relationships. Individuals with LOP facial types may benefit from a MMC clockwise rotation (CWR). Maxillo-mandibular complex is routinely expressed by a triangle, which can be rotated in a clockwise or counter-clockwise direction depending on aesthetics requirements (Figure 1) $(1,2)$.

OP manipulation was initially described by McCollum et al. in 1989 as a possible surgical design for class II occlusions and low OP angles cases (3). It was further reported by Kortebein et al. (in 1991) positive effects of maxillomandibular complex counter-clockwise rotation (CCWR) on increasing oropharyngeal airway space as well as improvement on facial balance when treating sleep apnea patients (4). OP manipulation also known as "MMC rotation" or "OP alteration" has become an accepted treatment design to be considered when treating DDF with satisfactory aesthetic results (5). There is paucity in scientific literature, however, on skeletal stability following CCR rotation of the jaws (6-8).

CCWR and CWR of the MMC post-surgical stability was first analysed by Chemello et al. (in 1994), and after this pioneer study, few studies also presented comparative data (7). Regarding CCWR post-surgical stability, concerns were raised due to problems related to increased posterior facial height, suprahyoid, pterygoid, and masseteric muscles stretching, and adverse effects on temporomandibular joint (TMJ). Some authors observed that skeletal stability after maxillomandibular complex CCWR is comparable to other mandibular surgical procedures. It was also reported that in order to obtain acceptable stability after CCWR, preoperative orthodontic treatment, proper surgical technique execution, and healthy TMJs are essential factors (7,8). Proffit et al. (in 1996), however, suggested that anterior facial height decrease by CCWR of mandible would jeopardise stability results (9). Rigid fixation development, enhancement of surgical techniques, preoperative diagnosis of TMJ pathologies and treatment were found to be mandatory to promote long-term stability in both CCWR and CWR of MMC $(2,7,10,11)$.

The aim of the present study is to evaluate postoperative stability of the MMC after CCWR and CWR submitted to orthognathic surgery to correct DDF. Two patients were submitted to CCWR and one patient to CWR. Due to the fact that CCWR and CWR rotations directly affects facial aesthetics and function, angular postoperative variations regarding maxilar prognathism, mandibular prognathism, pogonium prognathism, and condylar position were analysed. Linear measurements between $\mathrm{X}$-axis and A-point, B-point, and $\mathrm{Pg}$ were analysed as well.

\section{Methods}

The aim of the present pilot study is to evaluate the one-year postoperative skeletal stability after orthognathic surgery with CCWR rotation or with CWR. The study was conducted in accordance with the Declaration of Helsinki (as revised in 2013). The study was approved by national ethics committee of (NO. 2.658.262) and informed consent was taken from all patients involved. Three patients ( 2 male and 1 female) were submitted to orthognathic surgery to correct DDF. Each patient had surgery consisting of a Le Fort I maxillary osteotomy (one piece only) and bilateral sagittal split ramus osteotomies (BSSO). Le Fort I osteotomies 


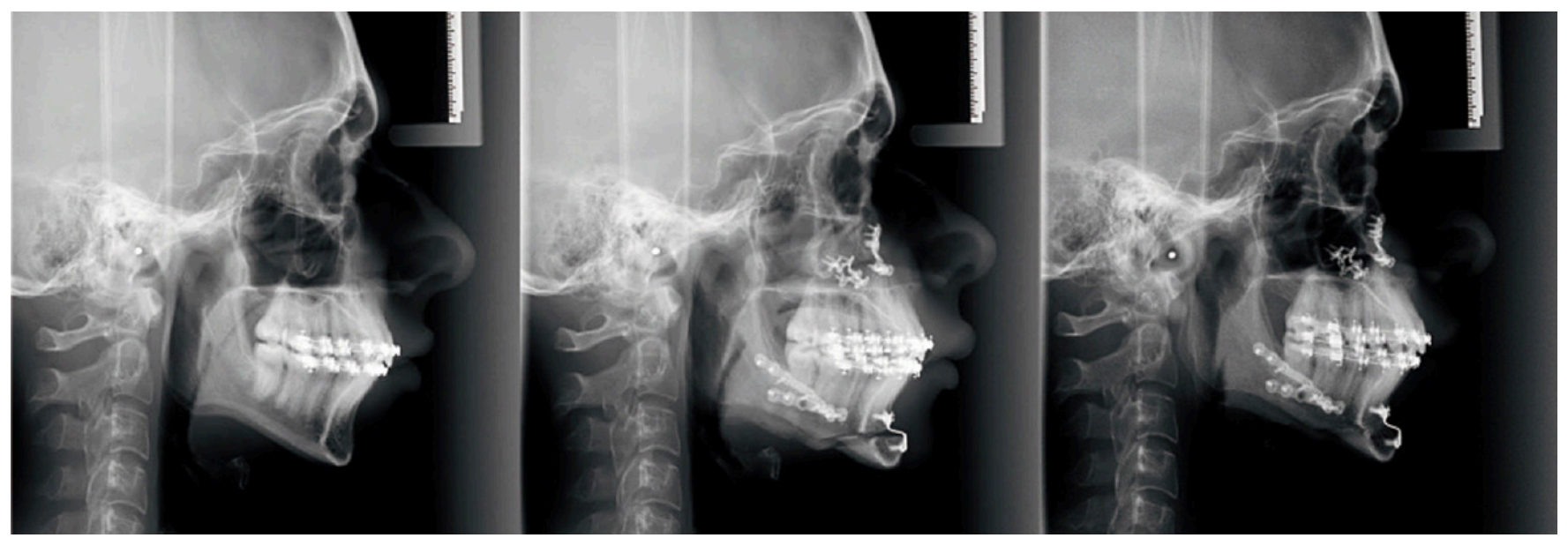

Figure 2 Lateral cephalometric radiographs were obtained in centric relation for each patient, 1 day before surgery (T1), 1 week after surgery (T2) and 1 year after surgery (T3). All radiographs were obtained utilising a standardised method on the same X-ray machine (Eagle 3-D Pan-Ceph, DaBi) operated by the same radiologist.

were fixated with 4 "L-shaped" $1.5 \mathrm{~mm}$ titanium plates (two screws above and two screws bellow the osteotomy line), two in the anterior region, and two in the posterior region of maxilla. BSSO osteotomies were fixated with $2 \mathrm{~mm}$ titanium plates and screws (two screws after and two screws before the vertical BSSO osteotomy), one plate in each side. In hybrid fixation, bi-cortical titanium screws of $2 \mathrm{~mm}$ were used in addition to plates and screws (each side). All patients also underwent genioplasty surgery.

Surgical movements and treatment planning were conducted as described by Wolford et al. All patients were treated with light training for a maximum of 4 weeks after surgery. The three patients were:

* Patient 1: male, 19 years old, dolichocephalic, submitted to double-jaw orthognathic surgery with CCWR rotation of the MMC and sliding genioplasty to correct class II DDF. The last follow-up time considered was 1 year. Four "L" shaped plates and sixteen screws were used in Le Fort I osteotomy fixation. Two straight plates and eight screws were used to BSSO fixation (one plate and 4 screws each side);

* Patient 2: male, 25-year-old, dolichocephalic, submitted to double-jaw orthognathic surgery with CCWR rotation of the MMC and sliding genioplasty to correct class II dentofacial deformity. The last follow-up time considered was 1 year after surgery. Four "L" shaped plates and 16 screws were used in Le Fort I osteotomy fixation. Two straight plates and eight screws were used to BSSO fixation (one plate and 4 screws each side). Two bi-cortical titanium screws of $2 \mathrm{~mm}$ (one each side) were used in addition to plates and screws (hybrid fixation);

* Patient 3: female, 28-year-old, brachycephalic, submitted to double-jaw orthognathic surgery with CWR rotation of the MMC and genioplasty to correct class III dentofacial deformity. The last follow-up time considered was 1 year after surgery. Four "L" shaped plates and sixteen screws were used in Le Fort I osteotomy fixation. Two straight plates and eight screws were used to BSSO fixation (one plate and 4 screws each side).

All patients signed the informed consent form, agreeing to participle in the study.

Lateral cephalometric radiographs were obtained in centric relation for each patient, one day before surgery (T1), 1 week after surgery (T2) and one year after surgery (T3). All radiographs were obtained utilising a standardised method on the same X-ray machine (Eagle 3-D Pan/Ceph) operated by the same radiologist (Figure 2). All pre and postoperative cephalometric radiographs were traced and digitalised by the same person using DDS-Pro Software (in 2018) (Figure 3). The following skeletal cephalometric landmarks were identified and digitalised: occlusal plane (OP), sella (S), nasion $(\mathrm{N})$, A-point, B-point, posterior nasal spine (PNS), gonion $(\mathrm{G})$, pogonium $(\mathrm{Pg})$, articulare $(\mathrm{Ar})$. Long-term postoperative angular changes of the occlusal plane (OP) were measured in relation to the $\mathrm{SN}$ plane (SN-OP). OP was defined according 

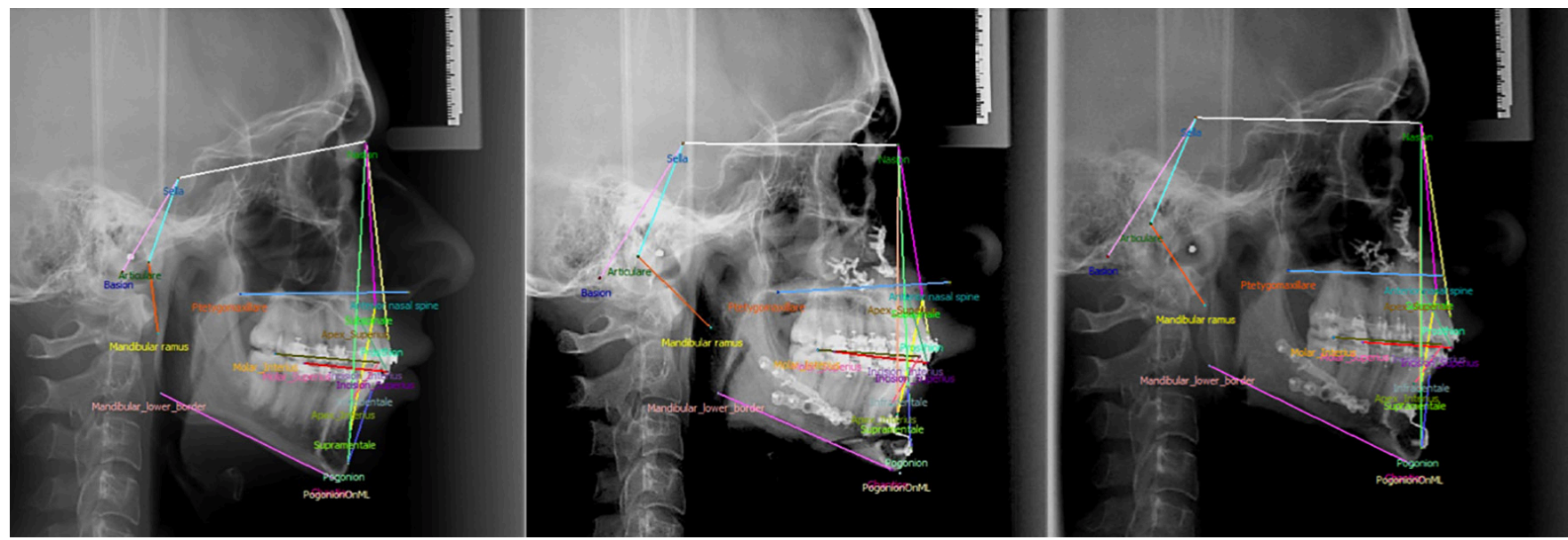

Figure 3 All pre- and postoperative cephalometric radiographs had their cephalometric landmarks identified, traced, and digitalised by the same person using DDS-Pro Software (in 2018).

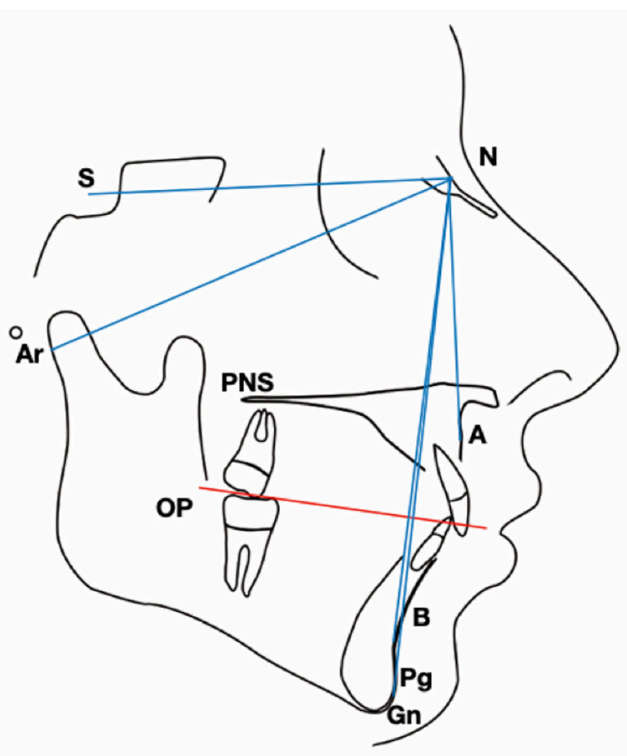

Figure 4 skeletal cephalometric landmarks were identified and digitalised: occlusal plane (OP), sella (S), nasion (N), A-point, B-point, posterior nasal spine (PNS), gonion $(\mathrm{G})$, pogonium $(\mathrm{Pg})$, articulare (Ar). Angles formed: SN-PO; SNA-point, SNB-point, $\mathrm{SN}-\mathrm{Pg}$, and SN-Ar.

to Downs: a line bisecting the overlapping cusps of the first molars and the incisal overbite. Long-term maxillary, mandibular, and pogonium prognathism angular changes were also recorded. Maxillary prognathism angular changes were measured by the angle formed between SN-A point (the most anterior point of maxilla). Mandibular prognathism angular changes were measured by the angle formed between SN-B point (deepest concavity anteriorly on mandibular symphysis). Pogonium prognathism angular changes were measured by the angle formed between $\mathrm{SN}-\mathrm{Pg}$. Condylar position angular changes were measured by the angle formed between $\mathrm{SN}-\mathrm{Ar}$ (Figure 4). All patients received pre and postoperative orthodontic treatment, hence, teeth were not used as reference.

Maxilar, mandibular, and pogonium prognathism linear changes were also recorded in millimeters by measuring the distance between the constructed $\mathrm{X}$ vertical axis to A point, $\mathrm{B}$ point, and $\mathrm{Pg}$, respectively (Figure 5).

In orthognathic surgery, a $10 \mathrm{~mm}$ vertical repositioning of the maxilla can be considered a large vertical movement of maxilla which is seldom indicated. A change of $1^{\circ}$ in the $\mathrm{OP}$ angle was recorded after a $10 \mathrm{~mm}$ vertical repositioning of the maxilla. With the above in mind, cases with an OP change of more than $+2^{\circ}$ were considered to be significant enough to be considered as deliberate clockwise rotation cases (CWR) while cases with an OP change of $-2^{\circ}$ and more negative were classified as deliberate counterclockwise rotation cases (CCWR). All three patients presented a $\mathrm{SN}-\mathrm{OP}$ angle change of more than $+2^{\circ} /-2^{\circ}$ so they were considered to be significant.

\section{Results}

\section{Angular measurements}

T1, T2, and T3 angular skeletal changes between SNOP, SN-A, SN-B, SN-Pg, and SN-Ar after orthognathic surgery associated with CCWR and CWR were recorded. 
Measurements were summarised in tables 1, 2, 3, 4, and 5 respectively. It was observed that the two patients submitted to orthognathic surgery with CCWR (patients 1 and 2), presented an important $\mathrm{OP}$ angle reduce on immediate postoperative (T2). The patient submitted to orthognathic surgery with CWR (patient 3), presented an important increase on occlusal plane angle on immediate postoperative (T2). All patients presented relapse of the conducted surgical movements in the last postoperative time (T3).

\section{Patient 1 (class II/CCWR) angular measurements}

* Regarding occlusal plane rotation (SN-OP angle),

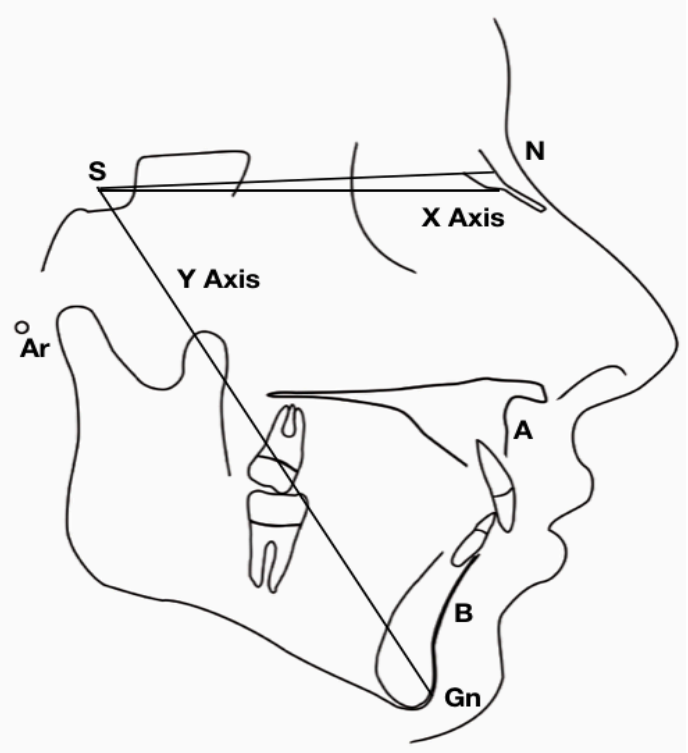

Figure 5 Constructed $\mathrm{X}$ axis and $\mathrm{Y}$ axis. $\mathrm{X}$ axis was used to measure horizontal changes in points $\mathrm{A}, \mathrm{B}$, and $\mathrm{Pg}$. it was observed a $2.17^{\circ}$ relapse between the two postoperative times (T3-T2) and an overall decrease of $0.19^{\circ}$ on the last postoperative time when compared to preoperative measures (T3-T1) (Table 1);

* Regarding maxillary prognathism (SN-A angle), it was observed an overall increase of $4.24^{\circ}$ on the last postoperative time when compared to preoperative measures (T3-T1) (Table 2);

* Regarding mandibular prognathism (SN-B angle) it was observed an overall increase of $15.56^{\circ}$ on the last postoperative time when compared to preoperative measures (T3-T1) (Table 3);

* Regarding pogonium prognathism (SN-Pg angle) it was observed an overall increase of $14.21^{\circ}$ on the last postoperative time when compared to preoperative measures (T3-T1) (Table 4);

* Regarding condylar position (SN-Ar) it was observed an overall decreased of $8.7^{\circ}$ on the last postoperative time when compared to preoperative measures ( $\mathrm{T} 3-$ T1) (Table 5).

\section{Patient 2 (class II/CCWR) angular measurements}

* Regarding occlusal plane rotation (SN-OP angle), it was observed a $0.54^{\circ}$ relapse between the two postoperative times (T2-T3) and an overall decrease of $4.15^{\circ}$ on the last postoperative time when compared to preoperative measures (T3-T1) (Table 1);

* Regarding maxillary prognathism (SN-A angle), it was observed an overall increase of $1.28^{\circ}$ on the last postoperative time when compared to preoperative measures (T3-T1) (Table 2);

* Regarding mandibular prognathism (SN-B angle) it was observed an overall increase of $9.24^{\circ}$ on the last postoperative time when compared to preoperative

Table 1 Values of the angles formed between SN-OP intersection regarding to occlusal plane rotation

\begin{tabular}{|c|c|c|c|c|c|c|}
\hline Patient number & $\begin{array}{l}\text { Class of deformity/ } \\
\text { movement performed }\end{array}$ & T1 (SN-OP) & T2 (SN-OP) & T3 (SN-OP) & $\begin{array}{l}\text { Postoperative relapse } \\
\text { (T3-T2) }\end{array}$ & $\begin{array}{l}\text { Overall OP rotation } \\
\text { (T3-T1) }\end{array}$ \\
\hline Patient 1 & Class II/CCWR & $6.37^{\circ}$ & $4.01^{\circ}$ & $6.18^{\circ}$ & $+2.17^{\circ}$ & $-0.19^{\circ}$ \\
\hline Patient 3 & Class III/CWR & $6.16^{\circ}$ & $16.13^{\circ}$ & $8.56^{\circ}$ & $-7.57^{\circ}$ & $+2.4^{\circ}$ \\
\hline
\end{tabular}

Cephalometric values were analysed in three different times: one-day preoperative (T1), one-week postoperative (T2), and one year postoperative (T3). Postoperative relapse was determined by subtracting T3 and T2 values. Overall OP rotation was determined subtracting T3 and T1 values. Patient 1 (class II) was submitted to double-jaw orthognathic surgery with CCWR and genioplasty with conventional fixation. Patient 2 (class II) was submitted to double-jaw orthognathic surgery with CCWR and genioplasty with hybrid fixation. Patient 3 (class III) was submitted to double-jaw orthognathic surgery with CWR and genioplasty with conventional fixation. 
Table 2 Values of the angles formed between SN-A point intersection regarding to maxilla angular prognathism

\begin{tabular}{|c|c|c|c|c|c|c|}
\hline Patient number & $\begin{array}{l}\text { Class of deformity/ } \\
\text { movement performed }\end{array}$ & T1 (SN-A) & T2 (SN-A) & T3 (SN-A) & $\begin{array}{l}\text { Postoperative } \\
\text { relapse (T3-T2) }\end{array}$ & $\begin{array}{c}\text { Maxilla Prognathism after } \\
\text { CCWR or CWR (T3-T1) }\end{array}$ \\
\hline Patient 1 & Class II/CCWR & $82.2^{\circ}$ & $89.41^{\circ}$ & $86.44^{\circ}$ & $-2.97^{\circ}$ & $+4.24^{\circ}$ \\
\hline Patient 3 & Class III/CWR & $98.1^{\circ}$ & $109.54^{\circ}$ & $98.76^{\circ}$ & $-10.78^{\circ}$ & $+0.66^{\circ}$ \\
\hline
\end{tabular}

Cephalometric values were analysed in three different times: one-day preoperative (T1), one-week postoperative (T2), and one year postoperative (T3). Postoperative relapse was determined by subtracting T3 and T2 values. Overall maxillary angular prognathism was determined by subtracting T3 and T1 values. Patient 1 (class II) was submitted to double-jaw orthognathic surgery with CCWR and genioplasty with conventional fixation. Patient 2 (class II) was submitted to double-jaw orthognathic surgery with CCWR and genioplasty with hybrid fixation. Patient 3 (class III) was submitted to double-jaw orthognathic surgery with CWR and genioplasty with conventional fixation.

Table 3 Values of the angles formed between SN-B-point intersection regarding to mandibular angular prognathism

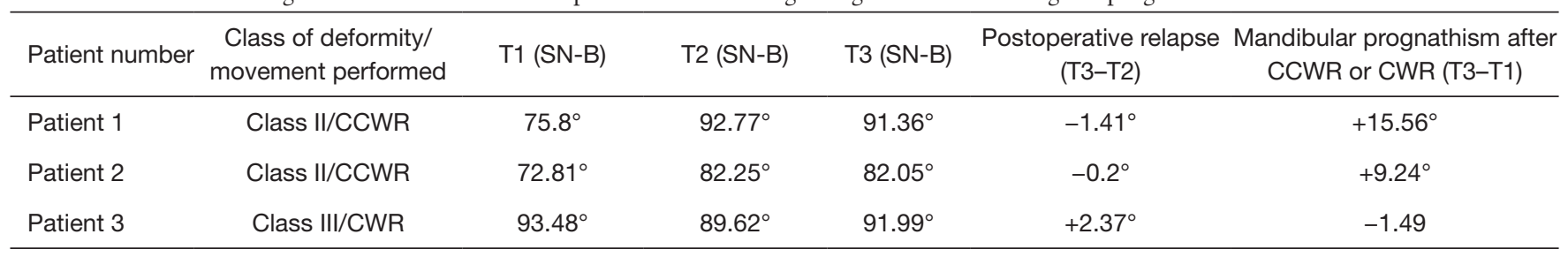

Cephalometric values were analysed in three different times: one-day preoperative (T1), one-week postoperative (T2), and one year postoperative (T3). Postoperative relapse was determined by subtracting T3 and T2 values. Overall mandibular angular prognathism was determined by subtracting T3 and T1 values. Patient 1 (class II) was submitted to double-jaw orthognathic surgery with CCWR and genioplasty with conventional fixation. Patient 2 (class II) was submitted to double-jaw orthognathic surgery with CCWR and genioplasty with hybrid fixation. Patients 3 (class III) was submitted to double-jaw orthognathic surgery with CWR and genioplasty with conventional fixation.

Table 4 Values of the angles formed between SN-Pg intersection regarding to pogonium angular prognathism

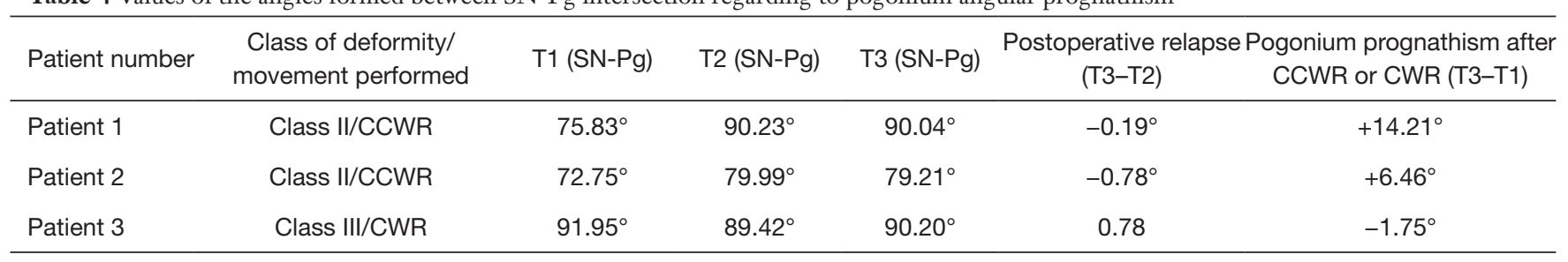

Cephalometric values were analysed in three different times: one-day preoperative (T1), one-week postoperative (T2), and one year postoperative (T3). Postoperative relapse was determined by subtracting T3 and T2 values. Overall pogonium angular prognathism was determined by subtracting T3 and T1 values. Patient 1 (class II) was submitted to double-jaw orthognathic surgery with CCWR and genioplasty with conventional fixation. Patient 2 (class II) was submitted to double-jaw orthognathic surgery with CCWR and genioplasty with hybrid fixation. Patient 3 (class III) was submitted to double-jaw orthognathic surgery with CWR and genioplasty with conventional fixation.

measures (T3-T1) (Table 3);

* Regarding pogonium prognathism (SN-Pg angle) it was observed an overall increase of $6.46^{\circ}$ on the last postoperative time when compared to preoperative measures (T3-T1) (Table 4);

* Regarding condylar position (SN-Ar) it was observed an overall decrease of $3.15^{\circ}$ on the last postoperative time when compared to preoperative measures (T3-T1) (Table 5).

It is important to highlight that in this patient, in addition to the two straight plates and eight screws used to BSSO fixation (one each side), two bi-cortical titanium 
Table 5 Values of the angles formed between SN-Ar intersection regarding to condylar angular position

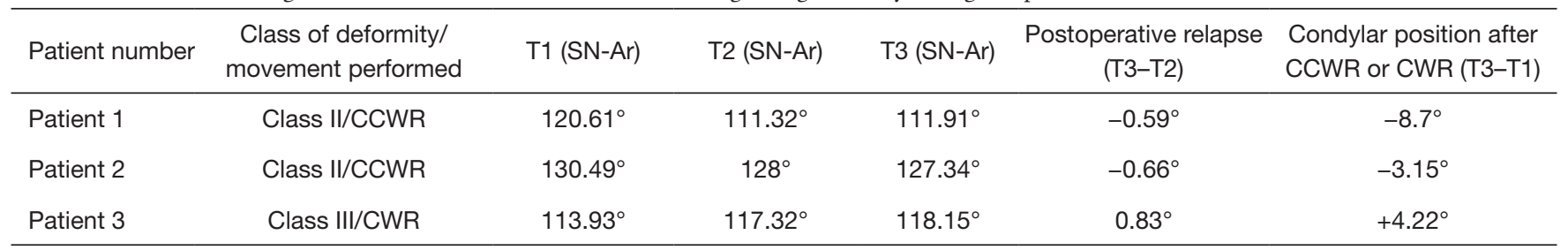

Cephalometric values were analysed in three different times: one-day preoperative (T1), one-week postoperative (T2), and one year postoperative (T3). Postoperative relapse was determined by subtracting T3 and T2 values. Overall condylar position was determined by subtracting T3 and T1 values. Patient 1 (class II) was submitted to double-jaw orthognathic surgery with CCWR and genioplasty with conventional fixation. Patient 2 (class II) was submitted to double-jaw orthognathic surgery with CCWR and genioplasty with hybrid fixation. Patients 3 (class III) was submitted to double-jaw orthognathic surgery with CWR and genioplasty with conventional fixation.

Table 6 Values of the distance between $\mathrm{X}$-axis and A-point/B-point/Pg between the last postoperative (T3) and preoperative (T1) times, demonstrating the amount of maxilla/mandibular/pogonium advancement/setback

\begin{tabular}{lccccccc}
\hline $\begin{array}{l}\text { Patient } \\
\text { number }\end{array}$ & $\begin{array}{c}\text { Class of deformity/ } \\
\text { movement performed }\end{array}$ & $\begin{array}{c}\text { X axis-A point } \\
\text { (T3-T1) }\end{array}$ & $\begin{array}{c}\text { X axis/B point } \\
\text { (T3-T1) }\end{array}$ & $\begin{array}{c}\text { X axis/Pg } \\
\text { (T3-T1) }\end{array}$ & $\begin{array}{c}\text { X axis/A point } \\
\text { relapse (T3-T2) }\end{array}$ & $\begin{array}{c}X \text { axis/B point } \\
\text { relapse (T3-T2) }\end{array}$ & $\begin{array}{c}X \text { axis/Pg relapse } \\
\text { (T3-T2) }\end{array}$ \\
\hline Patient 1 & Class II/CCWR & $+2.91 \mathrm{~mm}$ & $+11.82 \mathrm{~mm}$ & $+5.3 \mathrm{~mm}$ & $0.71 \mathrm{~mm}$ & $1.43 \mathrm{~mm}$ \\
Patient 2 & Class II/CCWR & $+1.79 \mathrm{~mm}$ & $+9.12 \mathrm{~mm}$ & $+7.61 \mathrm{~mm}$ & $0.69 \mathrm{~mm}$ & $1.45 \mathrm{~mm}$ & $0.61 \mathrm{~mm}$ \\
Patient 3 & Class III/CWR & $+1.33 \mathrm{~mm}$ & $-5.2 \mathrm{~mm}$ & $-2.14 \mathrm{~mm}$ & $0.12 \mathrm{~mm}$ & $0.79 \mathrm{~mm}$ & $0.28 \mathrm{~mm}$ \\
\hline
\end{tabular}

Postoperative relapse is also elucidated on the three last columns. It was determined by subtracting T3 and T2 values. Patient 1 (class II) was submitted to double-jaw orthognathic surgery with CCWR and genioplasty with conventional osteotomies fixation. Patient 2 (class II) was submitted to double-jaw orthognathic surgery with CCWR and genioplasty with hybrid fixation. Patient 3 (class III) was submitted to double-jaw orthognathic surgery with CWR and genioplasty with conventional fixation.

screws of $2 \mathrm{~mm}$ (one each side) were used as well.

\section{Patient 3 (class III/CWR) angular measurements}

* Regarding occlusal plane rotation (SN-OP angle), it was observed a $7.57^{\circ}$ relapse between the two postoperative times (T2-T3) and an overall increase of $2.4^{\circ}$ on the last postoperative time when compared to preoperative measures (T3-T1) (Table 1);

* Regarding maxillary prognathism (SN-A angle), it was observed an overall increase of $0.66^{\circ}$ on the last postoperative time when compared to preoperative measures (T3-T1) (Table 2);

* Regarding mandibular prognathism (SN-B angle) it was observed an overall decrease of $1.49^{\circ}$ on the last postoperative time when compared to preoperative measures (T3-T1) (Table 3);

* Regarding pogonium prognathism (SN-Pg angle) it was observed an overall decrease of $1.49^{\circ}$ on the last postoperative time when compared to preoperative measures (T3-T1) (Table 4);
* Regarding condylar position (SN-Ar) it was observed an overall increase of $4.22^{\circ}$ on the last postoperative time when compared to preoperative measures (T3-T1) (Table 5).

\section{Linear measurements}

$\mathrm{T} 1, \mathrm{~T} 2$, and $\mathrm{T} 3$ linear skeletal changes between $\mathrm{X}$-axis/ A-point, $\mathrm{X}$-axis/B-point, and $\mathrm{X}$-axis/Pg as result of orthognathic surgery associated with CCWR and CWR were recorded for the three patients involved. Measurements were summarised in Table 6.

\section{Patient 1 (class II/CCWR) linear measurements}

* Regarding the distance in milimetres from X-axis/ A-point a postoperative setback of $0.71 \mathrm{~mm}$ (T3-T2), and an overall advancement of $2.91 \mathrm{~mm}(\mathrm{~T} 3-\mathrm{T} 1)$ were observed;

* Regarding the distance in milimetres from X-axis/ B-point a postoperative setback of $1.43 \mathrm{~mm}$ (T3-T2); 
and an overall advancement of 11-82 mm (T3-T1) were observed;

* Regarding the distance in milimetres from $\mathrm{X}$-axis/ $\mathrm{Pg}$ a postoperative setback of $0.61 \mathrm{~mm}$ (T3-T2), and an overall advancement of $5.3 \mathrm{~mm}$ (T3-T1) were observed.

\section{Patient 2 (class II/CCWR) linear measurements}

* Regarding the distance in milimetres from $\mathrm{X}$-axis/A-point a postoperative setback of $0.69 \mathrm{~mm}$ (T3-T2), and an overall advancement of $1.79 \mathrm{~mm}$ (T3-T1) were observed;

* Regarding the distance in milimetres from X-axis/ B-point a postoperative setback of $1.45 \mathrm{~mm}$ (T3-T2), and an overall advancement of $9.12 \mathrm{~mm}$ (T3-T1) were observed;

* Regarding the distance in milimetres from X-axis/ $\mathrm{Pg}$ a postoperative setback of $0.49 \mathrm{~mm}$ (T3-T2), and an overall advancement of $7.61 \mathrm{~mm}(\mathrm{~T} 3-\mathrm{T} 1)$ were observed.

\section{Patient 3 (class III/CWR) linear measurements}

* Regarding the distance in milimetres from $\mathrm{X}$-axis/A-point a postoperative setback of $0.12 \mathrm{~mm}$ (T3-T2), and an overall advancement of $1.33 \mathrm{~mm}$ (T3-T1) were observed;

* Regarding the distance in milimetres from $\mathrm{X}$-axis/B-point a postoperative advancement of 0.79 $\mathrm{mm}$ (T3-T2), and an overall setback of $5.2 \mathrm{~mm}$ (T3T1) were observed;

* Regarding the distance in milimetres from $\mathrm{X}$-axis/Pg a postoperative advancement of $0.28 \mathrm{~mm}$ (T3-T2), and an overall setback of $2.14 \mathrm{~mm}$ (T3-T1) were observed.

\section{Discussion}

The main objective of the present study was to evaluate the one-year postoperative skeletal stability after orthognathic surgery associated with counter clock-wise rotation (CCWR) or clock wise rotation (CWR) movements. CCWR is described as being an anterior maxilla upward movement concomitant with a downward posterior maxilla repositioning. The greater the superior anterior maxilla repositioning the greater the OP angle decrease effect (12). CWR, on the other hand, is evident when the posterior nasal spine (PNS) moves upward and the anterior maxilla downwards. This movement of rotation contribute to mandibular incisors to advancement while the pogonium is rotated backwards reducing chin prominence, allowing an OP angle increase $(12,13)$.

Posterior maxilla downward movement in CCWR, was described previous described to cause lengthening of mandibular ramus a consequent stretch of masticatory muscles, which would lead to skeletal relapse (14). With the advent of today's most used plates and screws, an acceptable skeletal stability was suggested to be achieved and a poor muscle contribution to movement relapse was described. Poor skeletal stability with vertical loss of up to $70 \%$ of gained height following maxillary downward movement was described by Wolford et al. (15), Freihofer et al. (16), and Proffit et al. (9). Excellent long-term skeletal stability, however, have been reported by Bishara et al. (17), Proffit et al. (12), and Denison et al. (13). Stability after orthognathic surgery was also reported to be higher when soft tissues are relaxed and lower when soft tissues are stretched during surgery (14). However, this is debatable. Maxilla superior repositioning relaxes soft tissues and was associated with a good postoperative stability. Mandible advancement causes tissues stretch and was suggested to be not as stable as maxilla upwards movements (18). Neuromuscular adaptation was also suggested to achieve an excellent postoperative stability, which affects muscular length more than just muscular adaptation (19).

In the present study, patients 1 and 2 were submitted to orthognathic surgery with CCWR. Both patients 1 and 2 were classified as having class II dentofacial deformity, hence an important associated mandible advancement was observed. Patient 1 presented an immediate postoperative decrease on $\mathrm{OP}$ angle to $4.01^{\circ}\left(\mathrm{T} 1=6.37^{\circ}\right)$, showing an important CCWR of the MMC. 1 year after surgery, however, a $2.17^{\circ}$ relapse was observed $\left(\mathrm{T} 3=6.18^{\circ}\right)$. Maxillary, mandibular, and pogonium prognathism angles were increased and are related to positive aesthetic outcomes in class II patients. Linear advancements of A-point, B-point, and $\mathrm{Pg}$ were found to be 2.91, 11.82, and $5.83 \mathrm{~mm}$ also reported to have positive impacts in class II patients.

Patient 2 also presented an immediate postoperative decrease on $\mathrm{OP}$ angle to $3.45^{\circ}\left(\mathrm{T} 1=8.14^{\circ}\right)$, showing an important CCWR of MMC. One year after surgery, however, a $0.54^{\circ}$ relapse was observed $\left(\mathrm{T} 3=4.15^{\circ}\right)$, smaller in amplitude when compared to Patient 1's relapse. Maxillary, mandibular, and pogonium prognathism angles were increased and are related to positive aesthetic outcomes in 
class II patients. Linear advancements of A-point, B-point, and $\mathrm{Pg}$ were found to be $1,79 \mathrm{~mm}, 9,12 \mathrm{~mm}$, and $7,61 \mathrm{~mm}$ also reported to have positive impacts in class II patients. This patient was treated with a hybrid BSSO fixation, characterised to have one $1.5 \mathrm{~mm}$ titanium mini-plate and 4 screws associated with three bi-cortical $2 \mathrm{~mm}$ titanium screws each side. Evaluation of different fixation systems was conducted by Sigua-Rodriguez et al. (in 2019) in vitro for BSSO advancements higher than $10 \mathrm{~mm}$. It was observed that ideal fixation system for BSSO would be 2 titanium mini-plates, or 3 bi-cortical titanium screws, or customised titanium mini-plates (20). In the present study, patient 2 was the one who presented less relapse in both angular and linear measurements after orthognathic surgery.

Patient 3 was classified as having class III dento-facial deformity, and was submitted to orthognathic surgery associated with CWR, hence an important mandible setback was observed. The patient presented an immediate postoperative increase on $\mathrm{OP}$ angulation to $16.13^{\circ}$ $\left(\mathrm{T} 1=6.16^{\circ}\right)$. One year after surgery, however, a relapse of $7.57^{\circ}$ was observed. Maxillary prognathism angle was increased after orthognathic surgery. Mandibular and pogonium prognathism angles, however, were decreased and are related to positive aesthetic outcomes in class III patients. Linear advancement of A-point was reported to be $1.33 \mathrm{~mm}$. B-point and Pg linear setbacks were found to be $5.2,2.14 \mathrm{~mm}$ which are reported to have positive impacts in class III patients. Those findings were similar to other studies $(10,11,21)$.

Chemello et al. published in 1994, the first study aiming to compare maxillo-mandibular orthognathic surgery stability outcomes between patients with CWR (group $1, \mathrm{n}=14$ ) and patients with CCWR (group 2, n=27). No identified pre-existing TMJ issues were observed in those patients. Group 1 underwent orthognathic surgery with CWR. Average surgical increase in OP angulation was $5.6^{\circ}$. Statistically significant post-surgical modifications included anterior facial height change $(-0.8 \mathrm{~mm})$, ramus height change $(-0.3 \mathrm{~mm})$, and change in mandibular plane angle $\left(-0.5^{\circ}\right)$. Those changes were reported to be related, in part, to the removal of occlusal splint which allowed an autorotation of the mandible for the occlusion settling in. For group $2(\mathrm{n}=27)$ with CCWR, the surgical change average of the $\mathrm{OP}$ was $8.8^{\circ}$ with mandible advancing an average of $8 \mathrm{~mm}$ at $\mathrm{B}$ point and $10 \mathrm{~mm}$ at $\mathrm{Pg}$. Post-surgical instability was only observed a at A-point as it became $0.5 \mathrm{~mm}$ returned. The study suggested that selective OP alteration with CCWR and CWR, in the presence of healthy TMJs, using rigid fixation are stable procedures (7).

Reyneke et al. (in 2007), studied a 41 patients' group (33 female and 8 male patients) who were submitted to CCWR of the maxillo-mandibular complex and compared stability with a group of 25 patients (19 female and 6 male patients) with CWR and with a group of 22 patients (17 female and 5 male patients) with no change in the OP angle. In the CCWR group it was observed an OP angle decrease by $4.97^{\circ}$ just after surgery, and at longest followup, there was a significant increase by $1.6^{\circ}$ (relapse of $32 \%$ ). Maxillary advancement for this group was a mean of $3.32 \mathrm{~mm}$ at A-point with a non-significant relapse of $0.58 \mathrm{~mm}$. Mandible was advanced at B-point by $10.81 \mathrm{~mm}$, and at the longest follow-up, it moved posteriorly by a significant $1.85 \mathrm{~mm}$ (17\% of mandibular advancement). In the CWR group, OP angulation change was approximately $4.98^{\circ}$ and maxillary advancement at A-point was $2.73 \mathrm{~mm}$, whereas B point moved posteriorly in approximately $0.23 \mathrm{~mm}$. At the last follow-up, A-point moved posteriorly by $0.55 \mathrm{~mm}$ and $B$ point by a significant $0.61 \mathrm{~mm}$. Long-term change of the OP was significant, at $1.07^{\circ}(11)$. This study suggested relapse rates in both CCWR and CWR movements, and the first presented bigger angular and linear relapse amplitudes.

Maxilla was advanced in all three patients and the moderate postoperative relapse were similar to other reports $(11,20,22)$.

The present study further observed that patients submitted to CCWR of the MMC presented an overall decrease of SN-Ar angle after orthognathic surgery. Patients submitted to CWR, on the other hand, presented an overall increase on SN-Ar angle. Healthy and stable temporomandibular joints (TMJ) are reported to be important to achieve stable and predictable outcomes in orthognathic surgery associated with CCWR and CWR of the MMC. Patients with HOP facial type are reported to have increased incidence of pathologies of temporomandibular joint, including disk displacement and TMJ condylar resorption (22). As mandible is advanced, it is observed an increased TMJ load suggested to be related to supra-hyoid muscles stretching; for tissues to re-equilibrate according to the new skeletal position it would take months (23). Increased forces on TMJs could stimulate bone changes. If TMJs are in healthy conditions, this would not lead to articular pathologies. However, if the preoperative disc stability is thin or if preoperative TMJ pathology is present, TMJ loading can contribute to an increased pain experience, or condylar resorption $(23,24)$. No studies analysed SN-Ar angle position after CCWR and CWR. 


\section{Conclusions}

Regarding OP stability, results of the present article are consistent with of some previous published studies. More cases should be followed and more research in this area are necessary to validate these approaches to avoid unsuccessful cases or to anticipate unwanted results.

\section{Acknowledgments}

Funding: None.

\section{Footnote}

Data Sharing Statement: Available at https://fomm. amegroups.com/article/view/10.21037/fomm-20-32/dss

Conflicts of Interest: All authors have completed the ICMJE uniform disclosure form (available at https://fomm. amegroups.com/article/view/10.21037/fomm-20-32/coif). The authors have no conflicts of interest to declare.

Ethical Statement: The authors are accountable for all aspects of the work in ensuring that questions related to the accuracy or integrity of any part of the work are appropriately investigated and resolved. The study was conducted in accordance with the Declaration of Helsinki (as revised in 2013). The study was approved by national ethics committee of (No. 2.658.262) and informed consent was taken from all patients involved.

Open Access Statement: This is an Open Access article distributed in accordance with the Creative Commons Attribution-NonCommercial-NoDerivs 4.0 International License (CC BY-NC-ND 4.0), which permits the noncommercial replication and distribution of the article with the strict proviso that no changes or edits are made and the original work is properly cited (including links to both the formal publication through the relevant DOI and the license). See: https://creativecommons.org/licenses/by-nc-nd/4.0/.

\section{References}

1. Wolford LM, Chemello PD, Hilliard F. Occlusal plane alteration in orthognathic surgery--Part I: Effects on function and esthetics. Am J Orthod Dentofacial Orthop 1994;106:304-16.

2. Al-Moraissi EA, Wolford LM. Is Counterclockwise
Rotation of the Maxillomandibular Complex Stable Compared With Clockwise Rotation in the Correction of Dentofacial Deformities? A Systematic Review and MetaAnalysis. J Oral Maxillofac Surg 2016;74:2066.e1-e12.

3. McCollum AG, Reyneke JP, Wolford LM. An alternative for the correction of the Class II low mandibular plane angle. Oral Surg Oral Med Oral Pathol 1989;67:231-41.

4. Kortebein M. The effect of maxillary and mandibular advancement with decrease of occlusal plane on the posterior airway space. J Oral Maxillofac Surg 1991;49:93.

5. Reyneke JP, Evans WG. Surgical manipulation of the occlusal plane. Int J Adult Orthodon Orthognath Surg 1990;5:99-110.

6. Schendel SA, Epker BN. Results after mandibular advancement surgery: an analysis of 87 cases. J Oral Surg 1980;38:265-82.

7. Chemello PD, Wolford LM, Buschang PH. Occlusal plane alteration in orthognathic surgery--Part II: Longterm stability of results. Am J Orthod Dentofacial Orthop 1994;106:434-40.

8. Rosen HM. Occlusal plane rotation: aesthetic enhancement in mandibular micrognathia. Plast Reconstr Surg 1993;91:1231-40; discussion 1241-4.

9. Proffit WR, Turvey TA, Phillips C. Orthognathic surgery: a hierarchy of stability. Int J Adult Orthodon Orthognath Surg 1996;11:191-204.

10. Reyneke JP. Surgical manipulation of the occlusal plane: new concepts in geometry. Int J Adult Orthodon Orthognath Surg 1998;13:307-16.

11. Reyneke JP, Bryant RS, Suuronen R, et al. Postoperative skeletal stability following clockwise and counter-clockwise rotation of the maxillomandibular complex compared to conventional orthognathic treatment. Br J Oral Maxillofac Surg 2007;45:56-64.

12. Proffit WR, Phillips C, Turvey TA. Stability after surgicalorthodontic corrective of skeletal Class III malocclusion. 3. Combined maxillary and mandibular procedures. Int J Adult Orthodon Orthognath Surg 1991;6:211-25.

13. Denison TF, Kokich VG, Shapiro PA. Stability of maxillary surgery in open bite versus non-open bite malocclusions. Angle Orthod 1989;59:5-10.

14. Watzke IM, Turvey TA, Phillips C, et al. Stability of mandibular advancement after sagittal osteotomy with screw or wire fixation: a comparative study. J Oral Maxillofac Surg 1990;48:108-21; discussion 122-3.

15. Wolford LM, Hilliard FW. The surgical-orthodontic correction of vertical dentofacial deformities. J Oral Surg 1981;39(11):883-97. 
16. Freihofer HP. Surgical treatment of the short face syndrome. J Oral Surg 1981;39:907-11.

17. Bishara SE, Chu GW, Jakobsen JR. Stability of the LeFort I one-piece maxillary osteotomy. Am J Orthod Dentofacial Orthop 1988;94:184-200.

18. Forssell K, Turvey TA, Phillips C, et al. Superior repositioning of the maxilla combined with mandibular advancement: mandibular RIF improves stability. Am J Orthod Dentofacial Orthop 1992;102:342-50.

19. Ayoub AF, Stirrups DR, Moos KF. The stability of bimaxillary osteotomy after correction of skeletal Class II malocclusion. Int J Adult Orthodon Orthognath Surg 1993;8:155-70.

20. Sigua-Rodriguez EA, Caldas RA, Goulart DR, et al. Comparative evaluation of different fixation techniques for sagittal split ramus osteotomy in $10 \mathrm{~mm}$ advancements. Part two: Finite element analysis. J Craniomaxillofac Surg 2019;47:1015-9.

doi: $10.21037 /$ fomm-20-32

Cite this article as: Cavalcante RC, Delorenzi OG, Kluppel LE. Long-term skeletal stability following orthognathic surgery with counter-clockwise and clockwise rotation of the maxillo-mandibular complex: report of three cases. Front Oral Maxillofac Med 2021;3:2.
21. Tsai IM, Lin CH, Wang YC. Correction of skeletal Class III malocclusion with clockwise rotation of the maxillomandibular complex. Am J Orthod Dentofacial Orthop 2012;141:219-27.

22. Gonçalves JR, Cassano DS, Wolford LM, et al. Postsurgical stability of counterclockwise maxillomandibular advancement surgery: affect of articular disc repositioning. J Oral Maxillofac Surg 2008;66:724-38.

23. Esteves LS, Castro V, Prado R, et al. Assessment of skeletal stability after counterclockwise rotation of the maxillomandibular complex in patients with long-face pattern subjected to orthognathic surgery. J Craniofac Surg 2014;25:432-6.

24. Rocha VÁ, Neto AI, Rebello IM, et al. Skeletal stability in orthognathic surgery: evaluation of methods of rigid internal fixation after counterclockwise rotation in patients with class II deformities. Br J Oral Maxillofac Surg 2015;53:730-5. 